\title{
ESTEBAN ECHEVERRÍA: EL INTELECTUAL ANTE LA FORMACIÓN DEL ESTADO
}

\author{
Por \\ SAŨL SOSNOWSKI \\ University of Maryland
}

Reiteradamente Borges ha expresado la idea de que la historia argentina hubiera seguido una trayectoria más "positiva" si hubiera optado por Facundo en vez del Martín Fierro como libro nacional. Si bien la nostalgia por los componentes de un sistema social que desapareció ante las transformaciones radicales que sufrió el orden institucional argentino ha promovido la retórica del gaucho como centro de esa nostalgia, ese orden en sí ha seguido los preceptos marcadamente dependentistas anunciados festivamente por Sarmiento. Se vuelve a dar, de este modo, un distanciamiento fundamental entre la proyección folklórica de un núcleo de habitantes reducido ahora fuera del contexto que le dio lugar y el sistema mismo que promovió su aislamiento y anulación. Entre pronunciamientos categóricos y solemnes y las entonaciones de los lamentos se afincan los grandes debates que dan lugar a la definición de posiciones políticas actuales desde la relación intelectual ante Facundo y, en menor grado, ante los documentos redactados por Esteban Echeverría (1805-1851) y que bajo el rótulo de Dogma socialista ${ }^{1}$ han caracterizado el pensamiento de la Generación de 1837.

En un cuarto de siglo de vida definida como políticamente independiente, las Provincias Unidas del Río de la Plata ensayaron juntas de gobierno, triunviratos y directorios. ${ }^{2}$ Ensayos que no produjeron un modelo

\footnotetext{
1 Dogma socialista, edición crítica y documentada; prólogo de Alberto Palcos, La Plata, Universidad Nacional de La Plata, 1940 (sigue la segunda edición tirada por el autor en Montevideo, 1846, con las variantes respecto de la primera edición, Montevideo, 1839, titulada inicialmente Código o declaración de principios que constituyen la creencia social de la República Argentina). Cito por la edición de sus Obras completas, compilación y biografía de Juan María Gutiérrez, Buenos Aires, A. Zamora, 1951.

2 Véanse las gestiones de la Primera Junta de Gobierno, la Junta Grande, Los Triunviratos, la unificación del poder bajo el Directorio, las reacciones contra el Congreso de Tucumán (1816) y el Directorio por parte de los caudillos de las provincias, las reformas de Rivadavia, etc. Para un panorama continental de los ensayos gubernamentales, Tulio Halperín Donghi, Hispanoamérica después de la independencia; consecuencias sociales y económicas de la emancipación. Buenos Aires, Paidós, 1972.
} 
perfectible y que, por el contrario, representaron la exacerbación de intereses locales, la manifestación de la ingerencia mercantil inglesa en el orden económico y, en última instancia, las divisiones irreductibles que llevaron a la guerra civil. Los bandos y las proclamas oficiales, al igual que las muestras de los cancioneros populares de la época, ${ }^{3}$ señalan claramente que tras la retórica del control del poder subyace la presencia del control efectivo de la economía provincial - los intereses localistas dificultan en gran medida la proyección del control nacional-. La navegación de los ríos, la exportación de cueros, la posesión de los saladeros, los intereses de la burguesía citadina, se disputaban la posesión del Puerto. En términos literales, se trataba del control de la boca alimenticia que canalizaría todas las funciones de un cuerpo aún deforme pero ya sometido a las presiones de la integración de América Latina al mercado capitalista internacional.

Desde la perspectiva nacional inmediata parecía dirimirse un conflicto entre dos posiciones políticas que abogaban por sistemas gubernamentales diferentes. El conflicto que caracterizó a muchos países del continente al batirse unitarios y federales (en sus diversas nomenclaturas regionales) no logra dar cuenta del curso global que se planteaba al examinar los papeles que les eran asignados - y no elegidos directamente por voluntad propia o nacional- desde la metrópoli imperial. No sugiero con ello una clara dicotomía entre fuerzas que abogaban por la independencia nacional y aquéllas que sostenían que solo en una relación dependiente la Nación hallaría su verdadera función en el mundo de los pueblos cultos. La complejidad de las facciones y el circuito variado seguido por todos los bandos proponen una serie de cambios - no todos ellos de matices sutiles- que obedecían a la marcha de otras campañas de las que no estaban excentos los enfrentamientos militares.

En los Antecedentes de la Sociedad de Mayo y en la Ojeada retrospectiva, que examina los años que van desde el año 37 en que pronunció las "Palabras simbólicas" hasta su publicación en Montevideo en el Dogma socialista en 1846, Echeverría asienta su posición frente a los dos grande partidos - unitarios y federales - que se enfrentaron hasta la caída de Rosas en 1852. Si bien Echeverría no escatima acusaciones contra el sufragio universal propuesto por los unitarios y que, según él, ha sido el móvil utilizado por Rosas para instaurar la barbarie en Buenos Aires, tampoco deja lugar a dudas que en esta guerra él y los otros miembros de la Joven Generación se alían con los defensores de la civilización contra la barbarie. Tras estas proclamas y protestaciones, tras los postulados que prometen la Democracia, se vislumbra claramente una plataforma política

3 Cf. la referencia de Félix Weinberg en su estudio preliminar a M. Sastre, J. B. Alberdi, J. M. Gutiérrez y E. Echeverría, El salón literario, Buenos Aires, Hachette, 1958, p. 25. 
que establece el lugar que deberán ocupar los miembros de su generación en la reconstrucción del país.

Cercanos a los prịncipios de Mayo enunciados en 1810, la retórica independentista se afianza en la diferenciación. Ser "propio" es "no ser español"; responder a las exigencias nacionales es abandonar y desechar todo resquicio de la legislación española y de las costumbres heredadas de la Colonia. Responder a la "ley del ser" se aproxima cada vez más a la elegancia de los modales y los recursos europeos. Si por un lado se rechaza la imitación de lo europeo para acentuar las exigencias locales, por el otro el cuerpo se protege con el frac. Los índices del código vestimentario aluden directa e inequívocamente a la posición política de los partidos: insignia punzó vs. frac: barbarie vs. civilización. ${ }^{4} \mathrm{El}$ dato no es casual. También Sarmiento medirá a los miembros de la clase decente, profesional, de La Rioja según ese frac que todo lo anuncia y todo lo oculta. ${ }^{5}$ El enunciado del programa liberal que propone Echeverría parece cumplir una trayectoria análoga: la vestimenta que oculta lo esencial subraya su propio proyecto. Lo propio y lo ajeno, lo nacional y lo extranjero, el cuerpo asentado en la tierra nativa y el alma purificada en el olimpo francés, conjugan esa conducta. 6 Cuando Echeverría parte hacia Europa, la aduana lo identifica como comerciante; cuando cinco años más tarde vuelve de París, es "literato". Ambas definiciones se aúnan en los intereses que proclamará en estos documentos en los que se mantienen ambivalencias y ambigüedades propias del pensamiento que ordenará la república liberal burguesa.

La exaltación de la capacidad individual y la abstracción de los individuos al integrarse en la sociedad son asimilados en el Dogma según sus configuraciones específicas en la Asociación. Este proceso llevará eventualmente al "Progreso" que Echeverría define como vivir de acuerdo a "la ley del ser", para luego acotar, "el ser social" (p. 95). El proyecto también se ordena en torno a símbolos. No es casual que los enunciados del 37 se den a través de "Palabras simbólicas" que intentan organizar en

\footnotetext{
4 Véase la descripción del unitario en "El matadero". La cautiva- El matadero, fijación de los textos, prólogo, notas y apéndice iconográfico de Angel J. Battistessa, Buenos Aires, Peuser, 1958.

5 Domingo F. Sarmiento, Facundo, Civilización y barbarie, Buenos Aires, Espasa-Calpe, 1967, pp. 50-1. Es de sumo interés la edición prologada y comentada por Jorge Luis Borges, Buenos Aires, El Ateneo, 1974.

6 Véanse las lecturas elaboradas por David Viñas en "El escritor liberal romántico", De Sarmiento a Cortázar, Buenos Aires, Siglo Veinte, 1971, pp. 15-21. En el mismo libro, "Rosas, romanticismo y literatura nacional" y las referencias a los "viajes", pp. 142-65.
} 
breves fórmulas el ideario de su Generación. ${ }^{7}$ Desde el símbolo se pasa al programa y desde ese programa se plantea que sólo los que lo enuncian son capaces de llevar al país más allá de los límites impuestos por la fracasada política unitaria. Reflexión y acción sirven para impulsar el Dogma pero esa acción, en conjunción con los unitarios, cederá su lugar a la persuasión pacífica una vez derrotado el dictador. De este modo Echeverría sugiere que si bien la presencia de Rosas ha trastornado el orden lógico que debió haber seguido la Revolución (no se concibe en su pensamiento que ya los planteos de la Revolución de Mayo postularon la necesidad histórica de la irrupción de las guerras civiles) se podrán lograr los ideales de Mayo implantando primeramente una revolución moral que llevará al progreso que, a su vez, producirá lenta e inevitablemente una revolución material. El logro de estos fines se daría, según Echeverría, a través de una propaganda pausada pero incesante que acentuaría las creencias fraternizadas. Con una serie de topos a los que no fueron ajenos los que enunciaron fórmulas de juegos políticos más recientes, pero sin el cinismo que han prodigado décadas de apropiación, no se habla de personas sino de "patria", de "regeneración", de credos y dogmas que están por encima de la participación individual de los hombres. Son elementos formulados por seres poseedores de inteligencia, virtud, capacidades y méritos probados para llevar a cabo un plan que redundará en el beneficio del "pueblo".

La bondad de los educadores y propagandistas - no es otra la función que Echeverría le asigna a los hombres ilustrados que comparten su concepto del universo- es específica en cuanto a sus intereses. Al enunciar los ideales que deben ser seguidos, el primero es la libertad de prensa; el segundo problema que se plantean es la necesidad de definir y limitar la soberanía del pueblo; el tercero, la esencia y forma de la democracia representativa. Le siguen "algunas cuestiones económicas" y "algunos puntos de administración", además de la milicia nacional (pp. 61-2). Todo

7 Las quince "Palabras simbólicas" son: “1. Asociación. 2. Progreso. 3. Fraternidad. 4. Igualdad. 5. Libertad. 6. Dios, centro y periferia de nuestra creencia religiosa: el cristianismo su ley. 7. El honor y el sacrificio, móvil y norma de nuestra conducta social. 8. Adopcion de todas las glorias legítimas, tanto individuales como colectivas de la revolución; menosprecio de toda reputación usurpada e ilegítima. 9. Continuación de las tradiciones progresivas de la Revolución de Mayo. 10. Independencia de las tradiciones retrógradas que nos subordinan al antiguo régimen. 11. Emancipación del espíritu americano. 12 Organización de la patria sobre la base democrática. 13. Confraternidad de principios. 14. Fusión de todas las doctrinas progresivas en un centro unitario. 15. Abnegación de las simpatías que puedan ligarnos a las dos grandes facciones que se han disputado el poderío durante la revolución". La elaboración de estas "palabras simbólicas" que amplían las bases del ideario de Echeverría en pp. 128-65. La "Ojeada retrospectiva sobre el movimiento intelectual en el Plata desde el año 37", publicada en 1846, incorpora este material a su contexto específico desde la perspectiva de una lucha más extensa que la anticipada en su redacción inicial. Ver pp. 55-97. La dedicatoria a los "mártires de la patria" le otorga una mayor nota de urgencia a su llamado político. 
lo referente al poder gubernamental cae bajo la vaguedad de "la cosa pública". Esta ordenación, quizá más que ninguna otra, subraya la necesidad ya expresada por Echeverría de definir primero el "qué somos" y el "qué queremos ser" para saber hacia dónde "queremos/debemos encaminarnos".

La búsqueda de la historia propia, y aun la formulación de las preguntas, se ven viciadas por la fe en el llamado de un destino que los obliga a cumplir con la función política de ribetes mesiánicos (propio de los inicios de la historia) de salvar al pueblo de la violencia y encaminarlo a la tierra prometida del orden y el progreso. Dentro del contexto anárquico y el caos político, la formulación pre-positivista a favor del progreso, la paz y el orden - aun cuando estos son parcializados y dirigidos a una minoría en ascenso- tiene la virtud de apelar a aquellos que pueden ser integrados a ese sistema. El proyecto del Dogma era ser inteligible a todos para que una vez formada una "alianza formidable" se pudiera pulverizar "la impura liga de los egoístas, los malvados y los opresores". Del aniquilamiento de la "impura liga" surgiría la base sobre la que los altruistas y los dedicados al bien común ejecutarián los planes del futuro. El llamado "nuestro pueblo", es decir, todo aquel que se oponía a Rosas, o sea, todo aquel que compartiera siquiera en principio los enunciados básicos de la Joven Generación, cumpliría con la gran tarea de construir el país. Echeverría sugiere que Rosas y las guerras civiles fueron un mal paso. La cuenta nueva empezará con su fin. El advenimiento de la raza de los burgueses asentaría el futuro de la Nación en torno a bases que irían incorporando a díscolos e ignorantes a la estructura impuesta por la naturaleza, por esa misma fuerza que le otorgó a los elegidos la posibilidad de formar al pueblo y regir su curso.

El planeamiento racional, la educación cívica a través del partido como "patria en miniatura" constituiría un medio para informar sobre la abstracción de la Patria nacional, y todo ello llevaría al asentamiento en la unidad intrínseca tendiente a unir a todos los partidarios bajo una sola bandera. Echeverría cree firmemente que la educación transformaría a los habitantes en ciudadanos de una sociedad democrática. La Democracia como tradición, como principio y como institución, anularía toda oposición. Se disolverían las luchas de clase - no concebidas explícitamente en ese plan- en una sociedad que no plantearía otra relación que la coexistencia armónica y comprensiva de partes disímiles que contribuyen a la construcción de un todo que a todos beneficiaría por igual.

Sin que resulte necesario plantear las falacias históricas - dato decorativo de toda ilusión que el futuro ilustra con la utopía- cabe mencionar los siguientes datos, consecuentes, además, con todo el pensamiento enunciado por Echeverría y seguido por la política posterior. 
La tenencia de propiedad es un índice que separa a los ciudadanos aun en las etapas intermedias de la educación hacia el sufragio universal. La democracia se manifiesta en la igualdad de clases en cuanto todos tienen libertad individual, civil y política y en cuanto todos ejercen de mancomún la soberanía.

La bondad de los hombres - que algunos ven como característica de la visión romántica del hombre $\mathrm{y}$, por lo tanto, lo proyectan de un modo un tanto mecanicista a los planteos del Dogma- debe ser vista desde la perspectiva elitista nada ajena al creyente en la superioridad irracional de su causa. Tras el discurso de Echeverría se vislumbra como máxima recompensa la tenencia del poder y la capacidad de forjar una nación conforme a la proyección de los ideales propios de un núcleo reducido que enuncia esa plataforma programática. Todo énfasis en "lo nuestro" y en "lo práctico" exige el cuestionamiento del singular de ese "nuestro" y del fin inmediato de ese "práctico". El sometimiento de los hombres a doctrinas, a las buenas doctrinas, como única garantía de orden y de paz, no oculta en ningún momento los nombres de los que formulan esas doctrinas anónimas que emanan, a pesar de todo, de la posesión del privilegio. El ajuste de "la soberanía del pueblo" a "la soberanía por la razón del pueblo" supone una alteración radical de la organización nacional. Si por un lado Echeverría acusa a los unitarios de haber fallado al creer que la democracia se hallaba en las ciudades cuando debieron haberla buscado en la campaña, su propio proyecto - como el que Sarmiento explicita en 1845- implicaba la transformación de las características de la campaña en extensiones de los intereses de la ciudad, asiento único y verificable de la civilización. Aun si se aceptara que "masa" es igual a "instinto" que puede ser modificado mediante la educación para que el hombre no incurra en intentos fallidos como los que produjeron exilios y proscripciones, este planteo se apoya en otras raíces. El desarrollo pacífico y normal que Echeverría necesita para integrar a su país a la comunidad de las naciones cultas sólo podía darse mediante una integración económica que conllevaría la proyección y el asentamiento de los valores que propone como causa inicial. 8

El alegato de Echevarría a favor de su programa - a pesar de que podría resultar conflictivo un análisis que organizara la secuencia de la relación

8 Sobre el pensamiento de Echeverría, véanse: Tulio Halperín Donghi, El pensamiento de Echeverría, Buenos Aires, Sudamericana, 1951; Plácido Alberto Horas, Esteban Echeverría y la filosofia política de la Generación de 1837, San Luis, Universidad Nacional de Cuyo, 1950; Roger Labrousse, "Echeverría y la filosofía política de la Ilustración", Sur, Nos. 219-220 (1953), pp. 79-92; Raúl A. Orgaz, Echeverría y el saint-simonismo, Córdoba, Impr. Argentina, Rossi, 1934; Ricardo M. Ortiz, El pensamiento económico de Echeverría; trayectoria y actualidad, Buenos Aires, Raigal, 1953. Una interpretación de las funciones de la educación en Juan Mantovani, Echeverria y la doctrina de la educación popular, Buenos Aires, Perrot, 1957. 
base/superestructura y aún medios y fines- es coherente con el proyecto de ampliación de los ideales de la burguesía en ascenso y del establecimiento de las bases necesarias para la imposición de su orden. La versión liberal de la historia, que continúa traduciendo su vigencia real en la Argentina, acentúa estos ideales y, como toda versión oficial, los transforma en único módulo de percepción y en modelo único para el país y para la comprensión de su desarrollo.

Era inevitable que dado su contexto Echeverría planteara la formación de la Nación a partir de las contribuciones que solo podían aportar los miembros de su núcleo. ${ }^{9}$ Era igualmente inevitable que el paso por París transformara la percepción de sí mismo y que se definiera - y con razóncomo literato y no ya como comerciante. Las alianzas no dependian, sin embargo, de la definición inmediata sino del papel que el escritor, que el intelectual en general, podría cumplir dentro del orden que se vislumbraba desde el puerto. Se estaba ante una sociedad impulsada por fuerzas mercantiles, por un sistema burgués que garantizaría la tan ansiada y tan necesaria libertad de prensa que avala otras libertades restringidas a un club más selecto. $\mathrm{Y}$ esas libertades repercutirían mediante beneficios que exceden los límites de toda publicación. Dada una situación concreta que restringía en sus últimos años toda polémica, toda disensión, todo canal adecuado al flujo de ideas opuestas al régimen de Rosas, la exigencia de libertad de prensa como primer aspecto a ser discutido por la Joven Generación se hace coherente e igualmente vital.

La mirada que se centra en los intereses inmediatos y que proyecta los beneficios para todo un pueblo que no comparte necesariamente esa preocupación, promueve el surgimiento del ideario del Dogma como documento fundamental sobre el que se asienta toda historia del liberalismo argentino. La mirada privilegiada no puede ver otra cosa que la expansión de esos mismos privilegios en dosis adecuadas a los abributos prodigados por la naturaleza al resto de los hombres. Es así, entonces, que la función del intelectual en la formación de esa etapa apunta a la del poseedor de promesas y bondades abstractas. Para el visionario la materialidad es parte de un proyecto más lejano. Éste se llevaría a cabo luego de que los términos "progreso" y "democracia" hubieran aportado la seguridad -esta vez sí, seguridad material- basada en promesas

\footnotetext{
9 Una interpretación de sus propuestas en Hipólito Jesús Paz, La organización del estado argentino en el 'Dogma socialista' de la Asociación de Mayo, prologo del Dr. Carlos Ibarguren, Buenos Aires, El Ateneo, 1938. Sobre algunas ramificaciones y proyecciones del pensamiento de Echeverría: Alfredo L. Palacios, Esteban Echeverría, Albacea del pensamiento de Mayo, Buenos Aires, Claridad, 1951; Rómulo Bogliolo, Las ideas democráticas y socialistas de Esteban Echeverria, Buenos Aires, La vanguardia, 1937.
} 
dispensadas a lo largo de otros privilegios. Considerando la (posiblementebien-intencionada) redacción de un plan nacional que promulga objetivos precisos en torno al contenido de una educación que promoverá los privilegios de una clase, en esta etapa este intelectual debe ser visto como partícipe (algunos dirán, cómplice) directo en un proyecto cuyas repercusiones no han dejado de ser elaboradas hasta el día de hoy. 